\title{
Simultaneous thermogravimetric-mass spectrometric study on the pyrolysis behaviour of different rank coals
}

A Arenillas, F. Rubiera, J.J. Pis*

Instituto Nacional del Carbón, CSIC, Apdo. 73, 33080 Oviedo, Spain

\begin{abstract}
Simultaneous Thermogravimetry/Mass Spectrometry (TG/MS) was used to study the pyrolysis behaviour of an anthracite and three bituminous coals of different volatile matter content. This system was optimised by using calcium oxalate as a reference for calibration. A normalisation method that permitted a semiquantitative comparison between the volatile species of the coals was also developed. The instantaneous evolution of the volatile compounds was studied by means of temperature-programmed pyrolysis experiments. The peaks varied in shape, temperature and size and showed a marked dependence on coal rank. This can be attributed to the varying amounts of the different functional groups in the coals studied. Special attention was paid to the nitric oxide released during pyrolysis together with its precursor species.
\end{abstract}

Keywords: Coal pyrolysis; Thermal analysis; Mass spectrometry; Nitrogen compounds.

\section{Introduction}

Thermogravimetric analysis (TG) is a useful technique employed in coal research, since any information about the rate of weight loss either in an oxidant or inert atmosphere when temperature increases is a subject of main concern. However, coal is a very heterogeneous material and the temperature ranges of the various stages of decomposition overlap each other. While the overall process can be observed, the individual compounds evolved cannot be discerned from the thermoanalytical curves.

The above phenomena have led to the coupling of TG with other analytical techniques, which include chemical features. Consequently, the gases evolved can be assigned to the detected weight losses so that chemical information is correlated with the thermal event [1, 2]. Evolved gases may be analysed simultaneously or discontinuously. In the latter method, sampling of the evolved gases is intermittent. In the past, TG was combined with cold traps (CT) and was found to be particularly useful 
in the analysis of mixtures having components of different volatilities, in the study of decomposition mechanisms and characterisation of molecular structures [3]. More recently the separation power of gas chromatography (GC) has been extensively used [4]. The main advantages of GC is firstly that it enhances the capability for detection of minor products since several interferences are removed in the separation process and secondly isomer products can be separated.

However, if cold traps are used and if products are to be stored prior to analysis great care must be taken since chemical reactions between products are not to be excluded upon subsequent sample handling. Moreover, it seems clear that CT and GC are unsuitable for continuous monitoring of the weight change process/gas analysis.

For simultaneous thermal/gas analysis, mass spectrometry (MS) and Fourier transform infrared spectroscopy (FTIR) are the most common techniques. They can be used to identify the gaseous species emitted by a sample, according to their mass or their vibrational spectra. Both MS and FTIR techniques offer similar advantages such as real time analysis, qualitative and quantitative analysis and temporal/temperature resolution, though MS seems to have more compound specificity and higher sensitivity than FTIR. On the other hand, FTIR has the advantage that it can be used for handling heavy tar products and so is useful in pyrolysis studies. MS cannot resolve compounds with the same mass/charge ratio whereas FTIR detects only components with changing dipole moments.

To detect and analyse evolved volatiles, a variety of thermal-analysis methods and a combination of instruments can be used. A number of basic requirements must also be considered by the operator. These should include the choice of a suitable coupling method and gas flow conditions for the combined instruments together with an adequate response time. In this way simultaneous analysis and measurement repeatability can be achieved.

Some phenomena such as loss of gas by condensation at cold spots, low detection sensitivity because of heavy dilution with the purge gas, low-time-and-temperature resolution because of long transfer times, mixing with the purge gas by diffusion and by uncontrolled flow conditions, and variation in gas composition in the coupling interface, should be avoided [5].

The use of non-isothermal pyrolysis with associated evolved gas analysis provides a qualitative explanation of the pyrolysis behaviour of coal [6]. TG/FTIR data have been employed to study coal pyrolysis product distributions, decomposition kinetics, 
functional group composition [7] and as input data in a general model of coal devolatilisation [8]. Thermogravimetry combined with mass spectrometry (TG/MS) has also been applied to coal pyrolysis studies. Jakab et al. [9] used this technique to investigate the changes in coal structure caused by low temperature oxidation. In other studies mass spectrometry was also used during temperature-programmed pyrolysis to characterise structural modifications as well as side reactions produced by the selective chemical treatment of coal [10].

The deleterious emissions of nitrogen oxides during coal combustion is a subject of general concern. The increasing use of combustion modification-based technologies (i.e. low- $\mathrm{NO}_{\mathrm{x}}$ burners, furnace air and fuel-staging, etc.) has revived investigation into the nitrogen compounds formed during combustion [11-14]. Varey et al. [15] have employed TG/MS to study the reactive intermediates formed in the early stages of the combustion -devolatilisation step- in order to obtain a better understanding of the processes involved.

In this work mass spectrometry was used as the gas analysis technique. The main objective of the work was to obtain the best information about the pyrolysis behaviour of a range of coals through the optimum coupling between TG-MS. Several aspects of the coupling were studied, especial interest was placed on the response time of the spectrometric analysis. Different compounds evolved during the pyrolysis process were followed and correlated with the volatile matter content of the parent coals. The nitric oxide released during pyrolysis together with its precursor species were also analysed.

\section{Experimental}

The TG-MS system used consisted of a Setaram TGA 92 thermoanalyser coupled to a quadrupole mass spectrometer QME 125 from Balzers (m/z<200 a.m.u.). The ionisation of the analysed gas was performed by an axial beam ion source (100 eV). The ions separated according to their mass-to-charge ratio were detected by a Faraday collector.

Evolved gases passed through a heated $\left(160^{\circ} \mathrm{C}\right)$ stainless steel capillary with an i.d. of $0.15 \mathrm{~mm}$. The coupling interface between the thermoanalyser and the mass spectrometer fulfils two functions operating simultaneously as a gas-input system for the mass analyser and as a pressure reduction system. In order to eliminate cold points in the connecting line, the bottom of the thermoanalyser was heated to approximately 
$160^{\circ} \mathrm{C}$. Differences in the spectrometric response depending on whether this part of the equipment was heated or not were also evaluated.

Some authors $[15,16]$ have stated that, depending on the sampling probe position, it is possible to detect reactive species or estimate the gas composition under nearequilibrium conditions. Thus, experiments with the MS probe set in two different positions, at the exit of the TG and inside the furnace near the crucible, were performed to evaluate the influence of these positions on the MS detected species. The amount of the sample and the flow rate of the carrier gas were also evaluated in order to obtain the best operating conditions for both thermal and spectrometric analysis. Finally, the repeatability of the measurements was determined. Although a quantitative analysis was not performed in this work, a comparison of the intensity peak areas between the different samples was made (i.e. semiquantitative analysis) by using a normalisation procedure which will be described later.

Temperature-programmed pyrolysis experiments were performed under an argon flow rate of $50 \mathrm{~mL} \mathrm{~min}^{-1}$ and a heating rate of $15^{\circ} \mathrm{C} \mathrm{min}{ }^{-1}$ from room temperature to $850^{\circ} \mathrm{C}$. A sample mass of $25 \mathrm{mg}$ ground below $212 \mu \mathrm{m}$ was utilised. Four coals of different rank were used: a high volatile bituminous coal (CA), a medium volatile bituminous coal (TU), a low volatile bituminous coal (WE) and an anthracite (GI). The ultimate and proximate analyses for the coals studied are presented in Table 1.

\section{Results and discussion}

\subsection{Previous optimisation studies}

Regarding the coupling of the TG via the capillary to the MS, two possible probe position were tested: inside the furnace near the sample or at the exhaust of the thermogravimetric analyser. Both systems have advantages since the first position permits the detection of low concentrations of reactive intermediates, whereas coupling at the exit of the TG allows relative concentrations of the evolved gases at nearequilibrium conditions to be determined. However, the last configuration led to an increase in the response time of the MS signals, so that the thermal and spectrometric analyses were not synchronised. By placing the MS probe inside the thermobalance near the crucible, the response time was negligible and both analyses, thermogravimetric and spectrometric, can be considered as simultaneous. In addition, in the overall coal 
combustion process the first step is the evolution of the volatiles, the reaction of these compounds in an oxidant atmosphere will be very quick, so interest was focused on the instantaneous concentration of the pyrolysis products rather than on the equilibrium. The coupling system, therefore, was situated inside the furnace as near as possible to the sample.

The possibility of losses from condensation at cold points needs to be avoided. The only cold part in the system was the bottom of the thermobalance, and more specifically, the connecting part between the furnace and the heated capillary of the MS. In order to check for the presence of a cold point in the gas line, calcium oxalate monohydrate was used as a source of a potential condensable vapour $\left(\mathrm{H}_{2} \mathrm{O}\right)$. Two experiments, with and without the heating of the thermobalance bottom, were performed in $\mathrm{Ar}$ atmosphere with a heating rate of $15^{\circ} \mathrm{C} / \mathrm{min}$ from room temperature to $1000^{\circ} \mathrm{C}$. The decomposition steps of calcium oxalate monohydrate are the following:

$$
\begin{aligned}
& \text { I. } \mathrm{CaC}_{2} \mathrm{O}_{4} \cdot \mathrm{H}_{2} \mathrm{O} \stackrel{\Delta}{\longleftrightarrow} \mathrm{CaC}_{2} \mathrm{O}_{4}+\mathrm{H}_{2} \mathrm{O} \\
& \text { II. } \mathrm{CaC}_{2} \mathrm{O}_{4} \stackrel{\Delta}{\longrightarrow} \mathrm{CaCO}_{3}+\mathrm{CO} \\
& \text { III. } \mathrm{CaCO}_{3} \stackrel{\Delta}{\longrightarrow} \mathrm{CaO}+\mathrm{CO}_{2}
\end{aligned}
$$

The $\mathrm{H}_{2} \mathrm{O}$ obtained in the first decomposition step is very likely to condense at a cold point. Figure 1 presents the evolution of the decomposition of oxalate with and without the heating of the bottom of the thermobalance. As can be observed both analyses, thermal and spectrometric, were totally synchronised, the maximum of the compounds evolved corresponding to the maximum of the first derivative of the TG signal, DTG. Thermal analysis gave three steps of decomposition, the weight lost in each step and the temperature at which each step took place. The MS assigned each step to one compound, $\mathrm{H}_{2} \mathrm{O}$, $\mathrm{CO}$ and $\mathrm{CO}_{2}$, respectively.

Condensation in the thermobalance has been mentioned as a main source of fouling and 'memory' effects [3]. As can be seen in Figure 1, $\mathrm{H}_{2} \mathrm{O}$ may condense if cold points in the transfer line are not avoided. A wide peak of $\mathrm{H}_{2} \mathrm{O}$ was obtained due to 'memory' effects. Thus the external heating of the bottom of the thermobalance was applied in all experiments.

Next step in the optimisation was to obtain repeatability in the experiments. The pyrolysis of one of the coals, WE, was repeated several times in order to determine the 
reproducibility of the experiments. The same amount of sample and operating conditions were used in all cases. Figure 2a shows the original evolution profiles of the $\mathrm{m} / \mathrm{z} 2$ signal, belonging to $\mathrm{H}_{2}$, registered in three pyrolysis experiments. It can be observed that the signals presented reproducibility problems, the integrated peak area values being within the $1.21 \pm 0.3(\mathrm{E}-10 \mathrm{~A} \times \mathrm{min})$ range. Therefore a normalisation procedure had to be applied.

Other authors $[9,17]$ have used an argon isotope as internal reference to normalise the MS signals. In the present work the maximum value of the total intensity registered in the MS was used as the normalisation factor. This value depends on the state of the MS detector during the experiment and it can vary with time. It was assumed that the sensitivity of the MS detector did not vary during the experiment, as each run was of short duration. Each signal registered was also normalised with the sample mass used. In this way the profiles obtained could be compared.

Figure $2 \mathrm{~b}$ shows the result of the normalisation procedure and the repeatability obtained was very good. The integrated peak area values for the normalised signals were within $0.54 \pm 0.01\left(\min \times \mathrm{mg}^{-1}\right)$. After statistic study of the integrated peak area values, using Student's t test, the normalised signals gave peak area values with more precision. Thus the normalisation procedure was applied to the $\mathrm{m} / \mathrm{z}$ signals studied.

\subsection{Temperature-programmed pyrolysis}

Taking into account the optimisation and normalisation procedures above described, a series of bituminous coals with different volatile matter content and an anthracite were pyrolysed and analysed with the TG-MS system. The weight loss curves presented in Figure 3, revealed marked variations between the coals. From the curves, two characteristic parameters were obtained: the temperature of maximum rate of weight loss, $\mathrm{T}_{\max }$, and the initial thermal decomposition temperature, $\mathrm{T}_{\mathrm{i}}$, which are parameters that depend on the sample properties. These parameters are given in Table 2.

It can be seen that the characteristic temperatures, $\mathrm{T}_{\max }$ and $\mathrm{T}_{\mathrm{i}}$, presented higher values as coal rank increased. This effect indicates that thermally more labile groups are more abundant in lower rank coals. The macromolecular network is more stable and the labile bridges are progressively removed when coal rank increases. As a consequence, the volatile matter content decreased and the characteristic temperatures shifted to higher values with increasing rank. The lowest rank coal, CA, presented a maximum 
weight loss at approximately $115^{\circ} \mathrm{C}$ below the highest rank coal, GI. The percentage of weight loss for each coal studied followed a linear relationship $\left(r^{2}=0.9999\right)$ with the volatile matter content determined by the proximate analysis. Figure 3 shows that as the coal rank decreased, the slope of the weight loss curve increased, indicating that not only did the decomposition process begin at lower temperatures but also that it was a faster process.

With the TG-MS coupling, the information obtained from the pyrolysis experiments is more complete. The evolution of different volatile products could provide information on the chemical reactions occurring during thermal decomposition. Table 3 shows the most characteristic $\mathrm{m} / \mathrm{z}$ signals and the assigned ions. The integrated peak values in the decomposition range $\left(200-850^{\circ} \mathrm{C}\right)$ are also given. In this study qualitative and semiquantitative analysis, based on the comparison of the integrated peak areas, were performed. It needs to be pointed out that each compound (ion) detected in the MS has its own response factor and so the intensities of the same compound, for different samples, can be compared. In the case of the intensities of different $\mathrm{m} / \mathrm{z}$ signal, however, only the shape and the characteristic temperatures of the peak can be compared.

A comparison of the evolution of the main species produced during pyrolysis showed a relationship between volatile matter content and the species emission. In Figure 4 the evolution of $\mathrm{H}_{2}$ for the four coals studied is presented. The $\mathrm{H}_{2}$ peaks were detected in the last stages of thermal decomposition. $\mathrm{H}_{2}$ comes from the condensation of aromatic structures or the decomposition of heterocyclic compounds, processes that occur at a high temperature [6]. The anthracite GI showed very low $\mathrm{H}_{2}$ emissions due to the presence of highly condensed structures. The variation of hydrogen content between the coals CA, TU and WE is small as can be seen in Table 1. It might have been expected that with this small variation in the hydrogen content the emission of $\mathrm{H}_{2}$ during pyrolysis would be very similar for the three coals or even bigger in the case of coal $\mathrm{CA}$, due to its higher volatile matter content. However, the $\mathrm{H}_{2}$ evolved is, in fact, only a part of the hydrogen present in the coal (6-11\%) [18]. The mode of hydrogen occurrence is very much dependent on the coal type. The oxygen content plays an important role in the $\mathrm{H}_{2}$ release, so the higher the oxygen content the lower the $\mathrm{H}_{2}$ emission, due to the formation of $\mathrm{H}_{2} \mathrm{O}$. This is corroborated by the ultimate analysis values (Table 1) and the integrated peak areas (Table 3). 
Figure 5 shows the evolution of $\mathrm{H}_{2} \mathrm{O}$ during thermal decomposition. The lowest temperature peak reflected the moisture of the samples. The evolution of $\mathrm{H}_{2} \mathrm{O}$ at high temperature showed higher emissions for coal CA, in agreement with its higher oxygen content. The $\mathrm{H}_{2} \mathrm{O}$ evolution above $300^{\circ} \mathrm{C}$ is produced by decomposition of various oxygen-containing groups, mainly $\mathrm{OH}$ groups, leading to the formation of the pyrolysis water in a broad temperature range [9]. The peaks have a similar shape and appear at the same temperatures as other compounds (e.g. $\mathrm{CO}_{2}$ ). This has been also observed by other authors that have suggested that a single process is responsible for the release of both gases $[7,19]$.

Oxygen content also influences $\mathrm{CO}$ formation at a high temperature. The higher oxygen content in coal CA and the presence of more labile functional groups produced higher CO emissions, as can be seen in Figure 6. This figure shows a very well defined peak at about $490^{\circ} \mathrm{C}$, for coals CA, TU and WE, and a much lower peak at a higher temperature for coal GI. According to some authors [20] the source of CO is aryl ether linkages. For bituminous coals, the cleavage of alkyl aryl ethers has been found to be particularly important [6]. The temperature range of CO evolution is in good agreement with that reported by Burnham et al. [21]. CO released for the anthracite GI was very low. The maximum peak shifted at higher temperatures as the coal rank increased.

In the case of low rank coals $\mathrm{CO}_{2}$ is formed from aliphatic and aromatic carboxyl and carboxylate groups at low temperatures. At high temperatures, however, $\mathrm{CO}_{2}$ derive from thermally more stable ether-structures, quinones and oxygen-bearing heterocycles [22]. It has also been reported that the formation of $\mathrm{CO}_{2}$ from bituminous coals could be due to the existence of intramolecular carboxylic acid anhydrides [6]. In addition, $\mathrm{CO}_{2}$ can also be produced at high temperatures from the decomposition of carbonates. Chemical analysis of CA coal gave a $2.56 \% \mathrm{CO}_{2}(\mathrm{db})$ from carbonates, indicating that for this coal, part of the $\mathrm{CO}_{2}$ evolved at high temperature was due to carbonates decomposition.

As stated above, $\mathrm{CO}_{2}$ and $\mathrm{H}_{2} \mathrm{O}$, showed the same temperature dependence. If Figures 5 and 7 are compared, similar evolution profiles, and characteristic temperatures can be observed for both compounds. The coals CA, TU and GI present two well-defined peaks at 480 and $775^{\circ} \mathrm{C}$, but WE presents an extra peak at about $400^{\circ} \mathrm{C}$ for $\mathrm{H}_{2} \mathrm{O}$ and $\mathrm{CO}_{2}$ release. The integrated peak areas in Table 3 showed higher $\mathrm{CO}_{2}$ emission with decreasing coal rank. 
In Figure 8 the evolution of the $\mathrm{CH}_{4}$ with temperature for the four coals is presented. It can be seen in this figure that the formation of $\mathrm{CH}_{4}$ starts at temperatures higher than $400^{\circ} \mathrm{C}$ and reaches a maximum value at about $510^{\circ} \mathrm{C}$. A similar evolution was observed by other authors during pyrolysis of a bituminous coal [23]. $\mathrm{CH}_{4}$ in the pyrolysis of bituminous coals has been proposed to originate mainly from hydroaromatic and aryl methyl groups [24]. Other authors have obtained for coals with low carboxyl and hydroxyl groups, as is the case of the present work, good correlations between crosslinking and the appearance of $\mathrm{CH}_{4}[25,26]$. In Figure 8 it can be seen that the higher the volatile matter content, the more groups are likely to produce $\mathrm{CH}_{4}$ during pyrolysis processes. In this way the lower rank coal, CA, produced the highest emission of $\mathrm{CH}_{4}$ during thermal decomposition. Small amounts of $\mathrm{CH}_{4}$ were detected in the case of the anthracite GI, with a shift of the peak to higher temperatures. This shift could be due, as other authors have advanced [24], to the disappearance of hydroaromatics in anthracitic rank coals.

In spite of the number of works that have characterised the conventional pyrolysis species, such as $\mathrm{CO}, \mathrm{CO}_{2}, \mathrm{CH}_{4}, \mathrm{H}_{2}$, only a few works have focused on nitrogen compounds. NO is released in pyrolysis, but the most important nitrogen compounds evolved are the so-called NO precursors - $\mathrm{HCN}$ and $\mathrm{NH}_{3^{-}}$, and the reduced species $-\mathrm{N}_{2}$ and $\mathrm{N}_{2} \mathrm{O}$ - produced from homogeneous gas phase reactions and heterogeneous reactions on the char surface [27]. Due to interference problems it was not possible to distinguish between the reduced species, and both of them can contribute to the signal $\mathrm{m} / \mathrm{z} 14\left(\mathrm{~N}_{2}{ }^{++}\right)$. Thus this profile was assumed to be due to both species.

The ultimate analysis of the coals showed that the differences in nitrogen content were small. Coal rank influences the nature of the nitrogen-containing groups in coal. As the coal rank increases, nitrogen is contained in more stable structures, and less evolution is observed with temperature in an inert atmosphere. Thus the anthracite GI did not produce nitrogen compounds during pyrolysis, and probably all the nitrogen was retained in the char. Figures 9-11 compare nitrogen compounds released for the coals CA, TU and WE. The source of this nitrogen may be aliphatic compounds (amines) and some heterocyclic nitrogen (pyrrole, indole and carbazole groups) [28].

It is well-known that HCN is one of the main NO precursors [29]. In Figure 9 the HCN profile is presented, the highest maximum peak corresponding to the highest volatile matter content coal, CA. The integrated peak areas, Table 3, showed an important increase with the volatile matter content of the parent coal. A shift of the 
maximum peak to higher temperatures with an increase in coal rank was also observed. The NO profiles, Figure 10, presented a similar behaviour to HCN. The shape and characteristic temperatures of the peaks were nearly the same. This clearly indicates a connecting mechanism between both compounds. A decrease in the coal rank produced higher NO emissions during pyrolysis, mainly because of the higher concentration of the precursor compound (HCN) and the oxidant (oxygen-containing groups) species.

The reduced species $\left(\mathrm{N}_{2}{ }^{++}\right)$evolution profiles are presented in Figure 11. The $\mathrm{N}_{2}{ }^{++}$ maximum peaks shifted to higher temperatures, and they were not as symmetrical as the peaks of HCN and NO. A significant tail was observed at high temperatures, possibly because this signal did not only originate from any compound formed directly from functional groups in the parent coal, but also from later reactions. These reduction reactions can occur in the gas phase, or through heterogeneous reactions of NO on the char surface. The latter reactions take place mainly in the presence of oxygen. As in this work the experiments were carried out in an inert atmosphere, the main reduction reactions will occur via homogeneous mechanisms. $\mathrm{N}_{2} \mathrm{O}$ and $\mathrm{N}_{2}$, reduced species that contribute to $\mathrm{m} / \mathrm{z} 14$, will be produced from the oxidation of HCN by NO in the gas phase [30].

\section{Conclusions}

Optimisation of TG/MS coupling and the development of a normalisation procedure, allowed a semiquantitative comparison between different pyrolysis species from various rank coals, to be made. A decrease in the amount of the different compounds and a shift of their peaks towards higher temperatures with the decrease in coal rank was observed. The oxygen content of the coals played an important role in the $\mathrm{H}_{2}$ release as a higher oxygen content in the parent coal led to an increase in the production of $\mathrm{H}_{2} \mathrm{O}$. The release of the pyrolysis species was associated with the presence of different functional groups with different thermal stabilities in the coals. The evolution of the nitrogen compounds followed a similar trend to the other pyrolysis compounds. Under the conditions used in this work no nitrogen species were detected in the pyrolysis of the anthracite, while the peak temperatures for the NO increased from $500^{\circ} \mathrm{C}$ for the high volatile bituminous coal CA, to $510^{\circ} \mathrm{C}$ and $525^{\circ} \mathrm{C}$ for the medium and low volatile bituminous coals. 


\section{Acknowledgments}

Work carried out with a financial grant from the European Coal and Steel Community (Project 7220-ED/094). Fellowship support to A.Arenillas by DGICYT is also acknowledged. 


\section{References}

[1] M. Nali, F. Corana, L. Montanari and L. Pellegrini, J. Anal. Appl. Pyrolysis, 29 (1994) 15.

[2] W.M. Groenewoud and W. de Jong, Thermochim. Acta, 286 (1996) 341.

[3] K.G.H. Raemaekers and J.C. Bart, Thermochim. Acta, 295 (1997) 1.

[4] W.H. McClennen, R.M. Buchanan, N.S. Arnold, J.P. Dworzanski and L.C. Meuzelaar, Anal. Chem., 65 (1993) 2819.

[5] E. Kaisersberger and E. Post, Thermochim. Acta, 295 (1997) 73.

[6] K.H. van Heek and W. Hodek, Fuel, 73 (1994) 886.

[7] P.R. Solomon, M.A. Serio, R.M. Carangelo, R. Bassilakis, D. Gravel, M. Baillargeon, F. Baudais and G. Vail, Energy\&Fuels, 4 (1990) 319.

[8] P.R. Solomon, D.G. Hamblen, R.M. Carangelo, M.A. Serio and G.V. Deshpande, Energy\&Fuels, 2 (1988) 405.

[9] E. Jakab, F. Till and G. Várhegyi, Fuel Proc. Technol., 28 (1991) 221.

[10] J.P. Boudou, J. Bimer, P.D. Salbut, D. Cagniant and R. Gruber, Fuel, 73 (1994) 907.

[11] S.D. Brown and K.M. Thomas, Fuel, 72 (1993) 359.

[12] W.X. Wang, S.D. Brown, K.M. Thomas and J.C. Crelling, Fuel, 73 (1994) 341.

[13] A.W. Harding, S.D. Brown and K.M. Thomas, Comb. \& Flame, 107 (1996) 336.

[14] J.B. Milligan, K.M. Thomas and J.C. Crelling, Fuel, 76 (1997) 1249.

[15] J.E. Varey, C.J. Hindmarsh and K.M. Thomas, Fuel, 75 (1996) 164.

[16] J.M. Jones, A.W. Harding, S.D. Brown and K.M. Thomas, Carbon, 33 (1995) 833.

[17] P. Szabó, P., G. Várhegyi, F. Till and O. Faiz, J. Anal. Appl. Pyrolysis, 36 (1996) 179.

[18] W. Xu and A. Tomita, Fuel, 66 (1987) 627.

[19] S. Niksa, Energy\&Fuels, 10 (1996) 173.

[20] P.R. Solomon and D.G. Hamblen, in R.H. Schlosberg (Ed.), Chemistry of Coal Conversion, Plenum Press, New York, 1985, p. 246.

[21] A.K. Burnham, M.S. Oh, R.W. Crawford and A.M. Samoun, Energy\&Fuels, 3 (1989) 42.

[22] N. Berkowitz, in L.L. Anderson (Ed.), Coal Science and Technology 7, The Chemistry of Coal, Elsevier, Amsterdam, 1985, p. 233.

[23] J.V. Ibarra and R. Moliner, J. Anal. Appl. Pyrolysis, 20 (1991) 171. 
[24] S. Charpenay, M.A. Serio, R. Bassilakis and P.R. Solomon, Energy\&Fuels, 10 (1996) 19.

[25] P.R. Solomon, D.G. Hamblen, M.A. Serio, Z. Yu and S. Charpenay, Fuel, 72 (1993) 469.

[26] J.V. Ibarra, R. Moliner and M.P. Gavilan, Fuel, 70 (1991) 408.

[27] J. Leppälahti and T. Koljonen, Fuel Proc. Technol., 43 (1995) 1.

[28] K. Stanczyk and J.P. Boudou, Fuel, 73 (1994) 940.

[29] P. Chambrion, H. Orikasa, T. Suzuki, T. Kyotani and A. Tomita, A., Fuel, 76 (1997) 493.

[30] B. Feng, H. Liu, J. Yuan, Z. Lin, D. Liu. and B. Leckner, Energy\&Fuels, 10 (1996) 203. 
Table 1. Proximate and ultimate analysis of the coals.

\begin{tabular}{|c|c|c|c|c|c|c|c|c|}
\hline \multirow[t]{2}{*}{ Coal } & \multicolumn{3}{|c|}{ Proximate analysis (wt\%) } & \multicolumn{5}{|c|}{ Ultimate analysis (wt\%, daf) } \\
\hline & Moisture & Ash (db) & $\mathrm{VM}(\mathrm{db})$ & $\mathrm{C}$ & $\mathrm{H}$ & $\mathrm{N}$ & S & $\mathrm{O}$ (diff.) \\
\hline CA & 1.4 & 7.6 & 37.7 & 84.3 & 5.6 & 1.8 & 1.6 & 6.7 \\
\hline TU & 0.9 & 7.1 & 26.1 & 87.5 & 5.1 & 1.8 & 1.5 & 4.1 \\
\hline WE & 0.7 & 7.9 & 17.4 & 91.1 & 4.8 & 1.1 & 0.7 & 2.2 \\
\hline GI & 0.3 & 9.0 & 4.2 & 94.4 & 2.1 & 1.0 & 0.9 & 1.7 \\
\hline
\end{tabular}

db: dry basis

daf: dry ash free basis

diff: calculated by difference 
Table 2. Characteristic parameters from temperature-programmed pyrolysis profiles of the coals.

\begin{tabular}{lcccc}
\hline & CA & TU & WE & GI \\
\hline $\mathrm{T}_{\mathrm{i}}\left({ }^{\circ} \mathrm{C}\right)$ & 218 & 273 & 344 & 603 \\
$\mathrm{~T}_{\max }\left({ }^{\circ} \mathrm{C}\right)$ & 470 & 519 & 550 & 685 \\
\hline
\end{tabular}


Table 3. Integrated peak areas of the gaseous compounds evolved during the pyrolysis of the coals.

\begin{tabular}{|c|c|c|c|c|c|}
\hline \multirow{2}{*}{$\mathrm{m} / \mathrm{z}$} & \multirow{2}{*}{ Assignation } & CA & TU & WE & GI \\
\hline & & \multicolumn{4}{|c|}{ 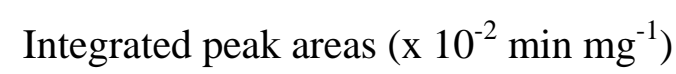 } \\
\hline 2 & $\mathrm{H}_{2}^{+}$ & 26.81 & 28.90 & 29.08 & 3.03 \\
\hline 14 & $\mathrm{~N}_{2}^{++}$ & 1.31 & 1.00 & 0.60 & 0.02 \\
\hline 16 & $\mathrm{CH}_{4}^{+}$ & 9.82 & 7.62 & 4.38 & 0.27 \\
\hline 27 & $\mathrm{HCN}^{+}$ & 1.14 & 0.64 & 0.32 & - \\
\hline 28 & $\mathrm{CO}^{+}$ & 8.08 & 5.57 & 2.62 & 0.60 \\
\hline 30 & $\mathrm{NO}^{+}$ & 0.35 & 0.20 & 0.13 & - \\
\hline 44 & $\mathrm{CO}_{2}^{+}$ & 3.38 & 2.07 & 2.27 & 0.61 \\
\hline
\end{tabular}



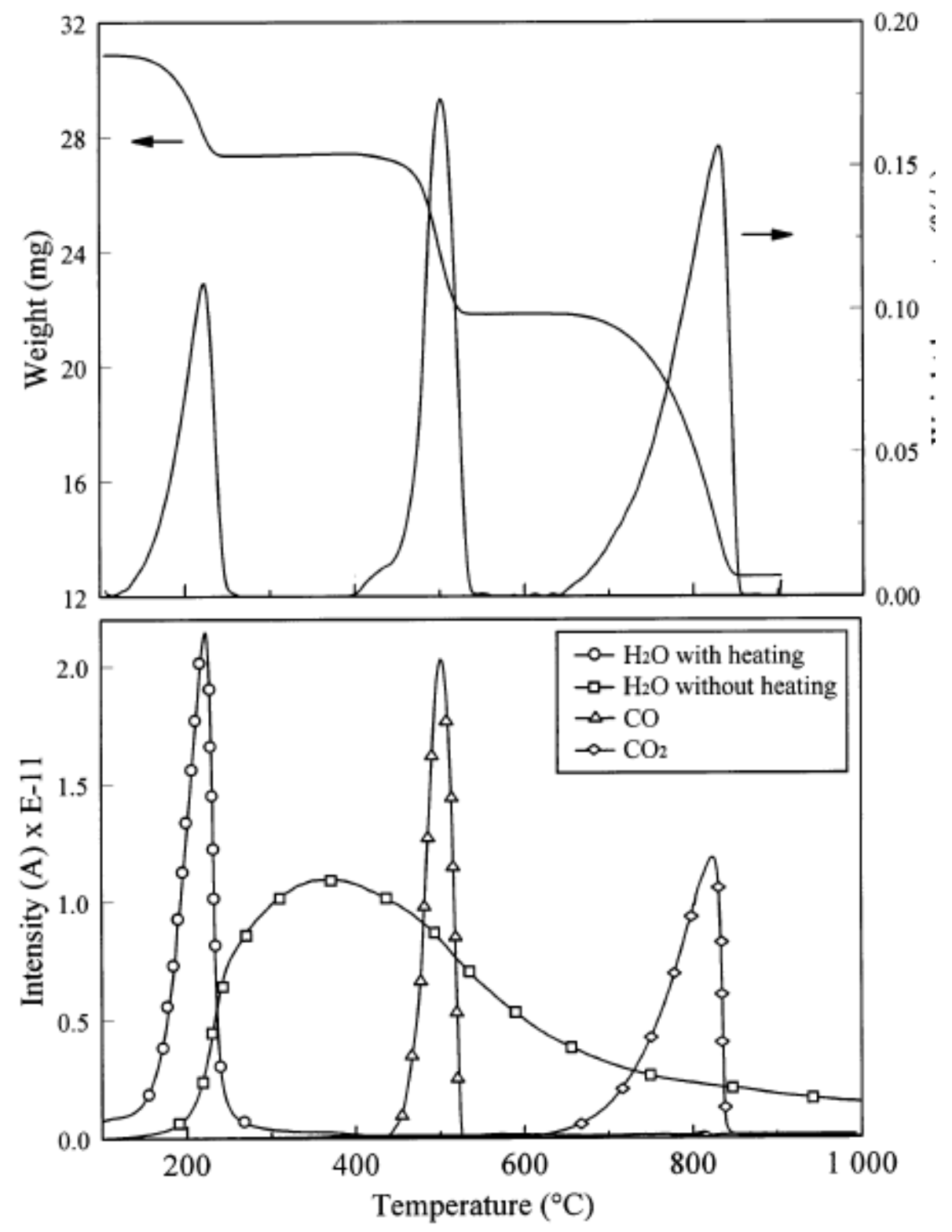

Figure 1. Comparison between the thermogravimetric curves and the $\mathrm{H}_{2} \mathrm{O}, \mathrm{CO}$ and $\mathrm{CO}_{2}$ mass spectrometric signals for the decomposition of calcium oxalate under argon. 

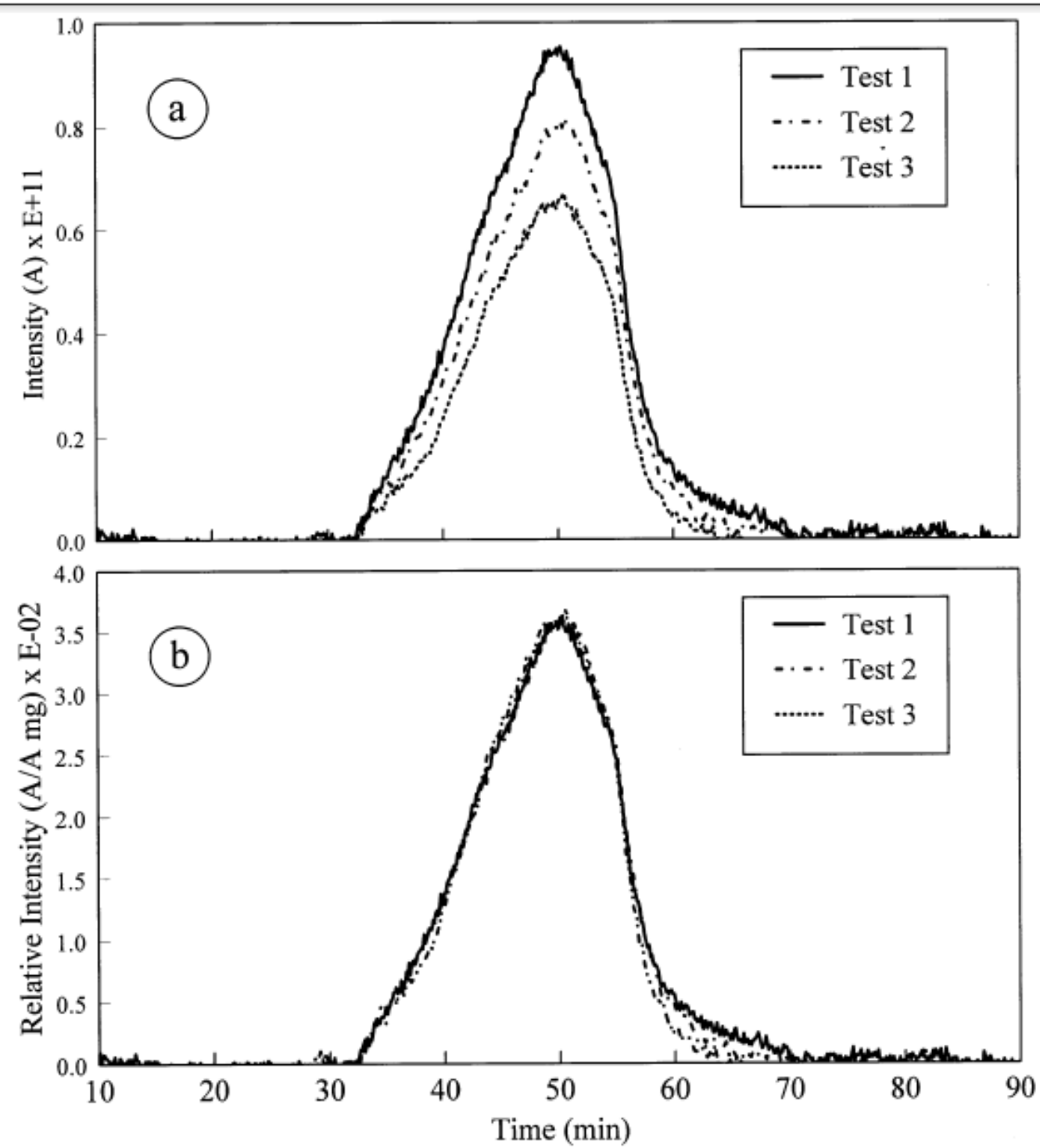

Figure 2. $\mathrm{H}_{2}$ evolution profiles during pyrolysis of a bituminous coal: a) before normalisation, b) after normalisation. 


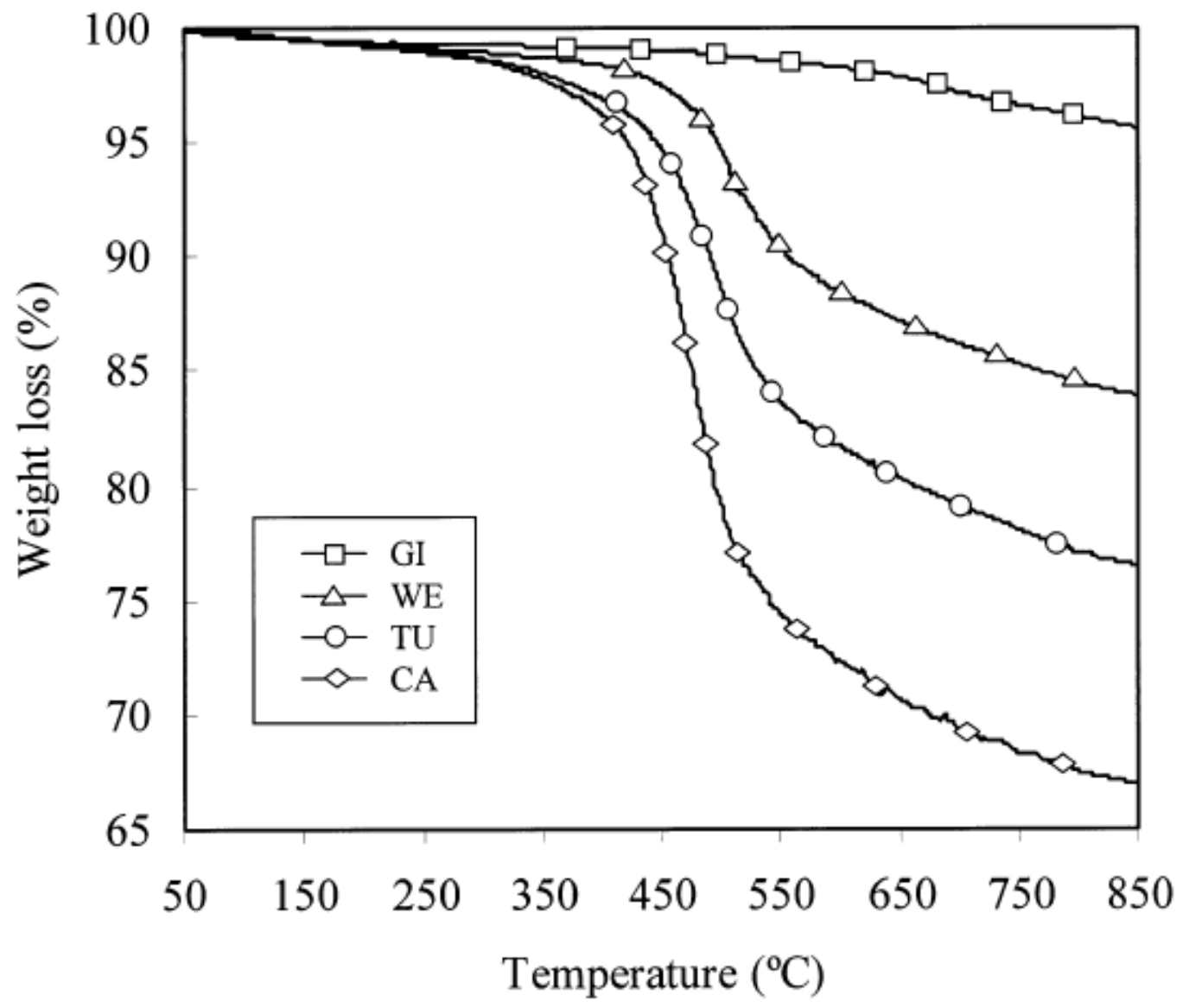

Figure 3. Thermogravimetric weight loss curves during the pyrolysis of the four coals used in this work. 


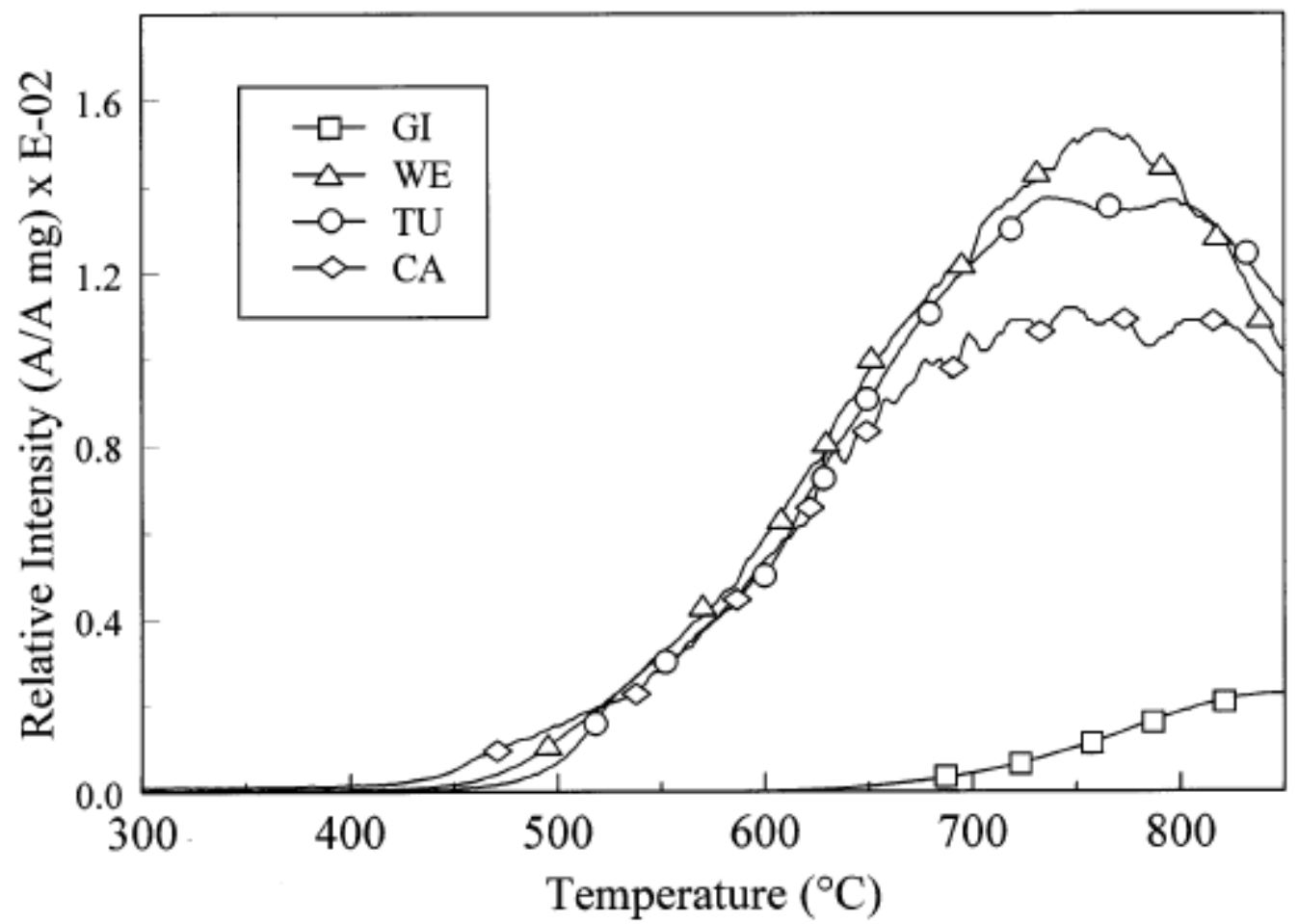

Figure 4. $\mathrm{H}_{2}$ evolution curves followed by MS during pyrolysis of the four coals. 


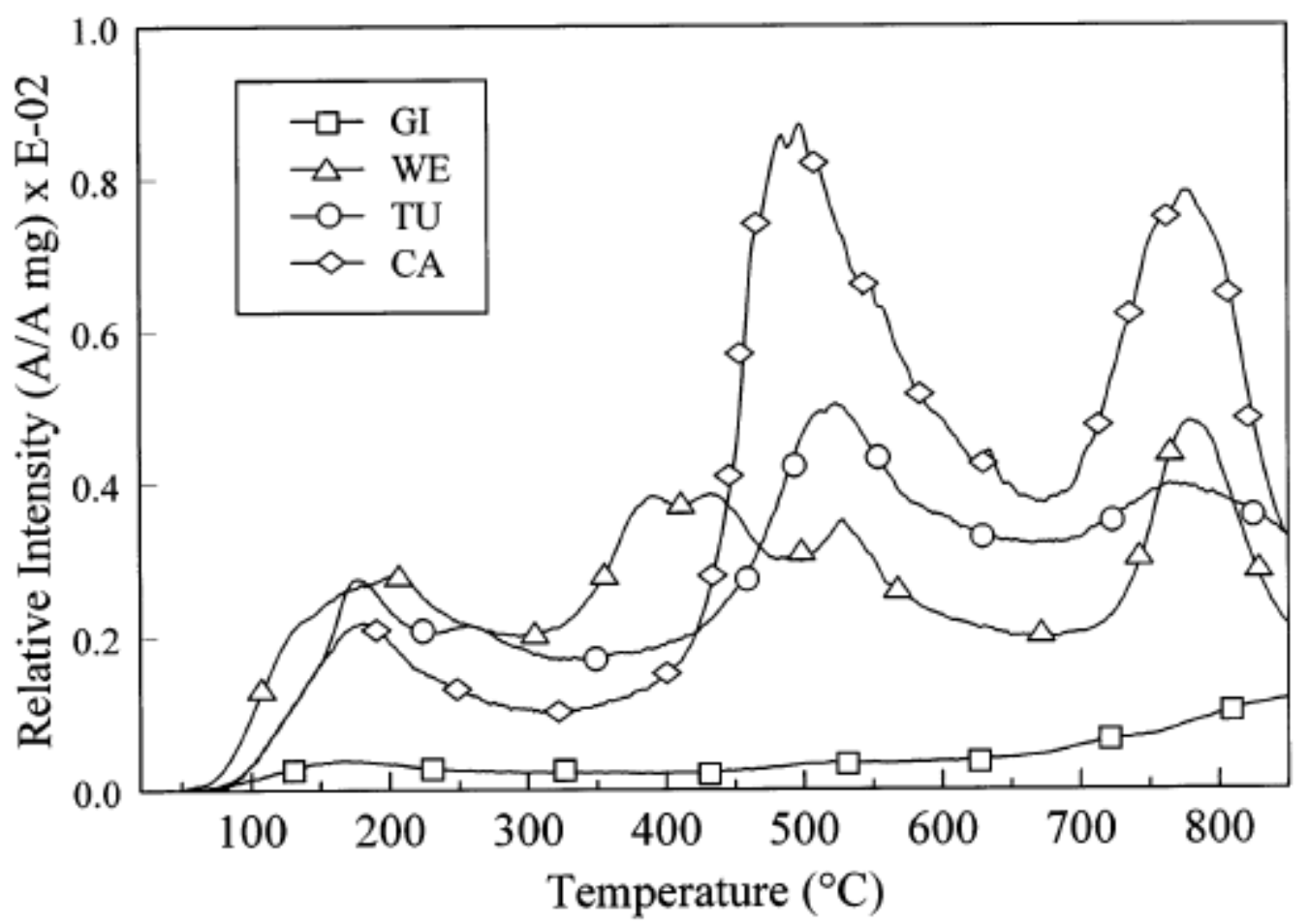

Figure 5. $\mathrm{H}_{2} \mathrm{O}$ evolution curves followed by MS during pyrolysis of the four coals. 


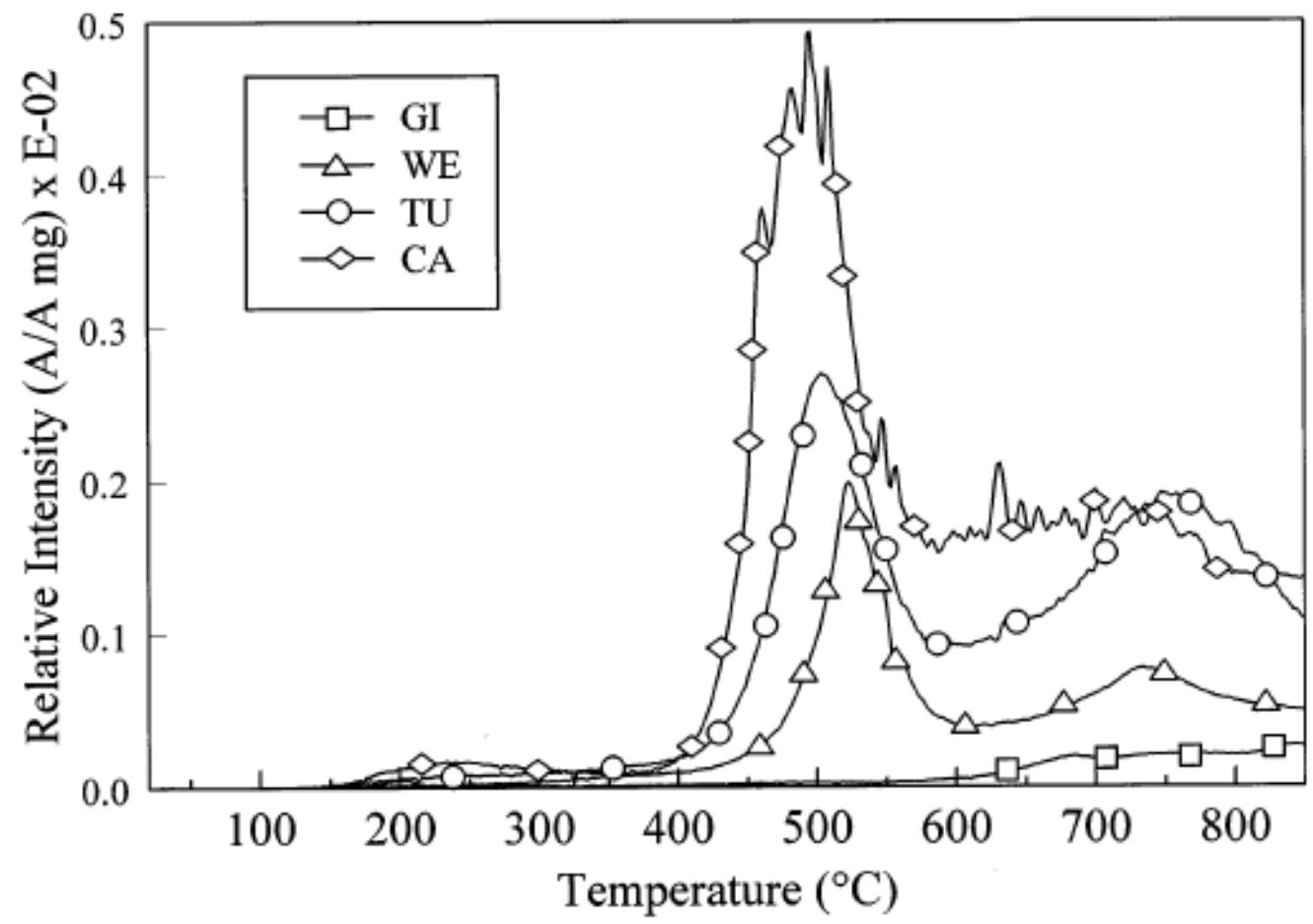

Figure 6. CO evolution curves followed by MS during pyrolysis of the four coals. 


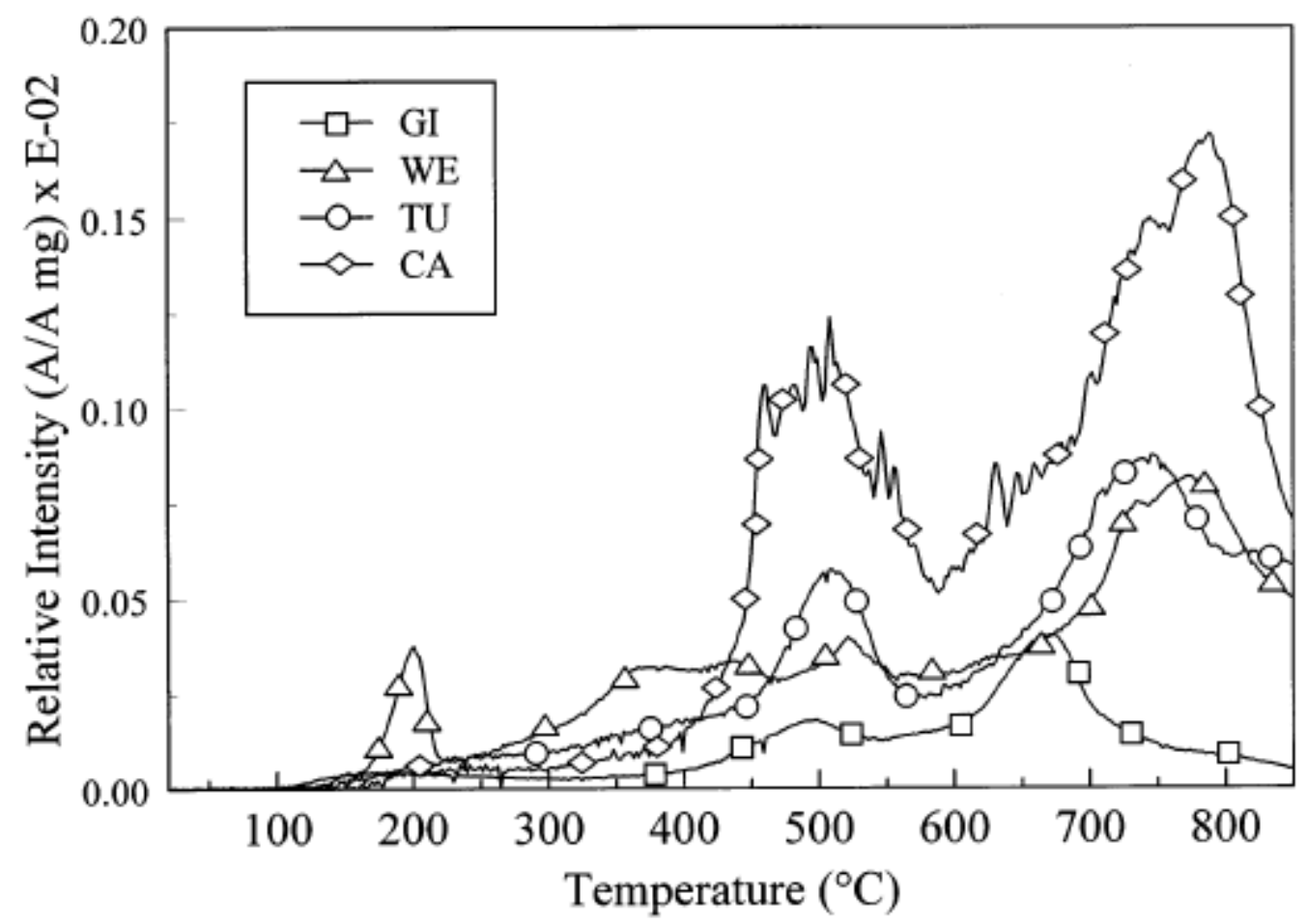

Figure 7. $\mathrm{CO}_{2}$ evolution curves followed by MS during pyrolysis of the four coals. 


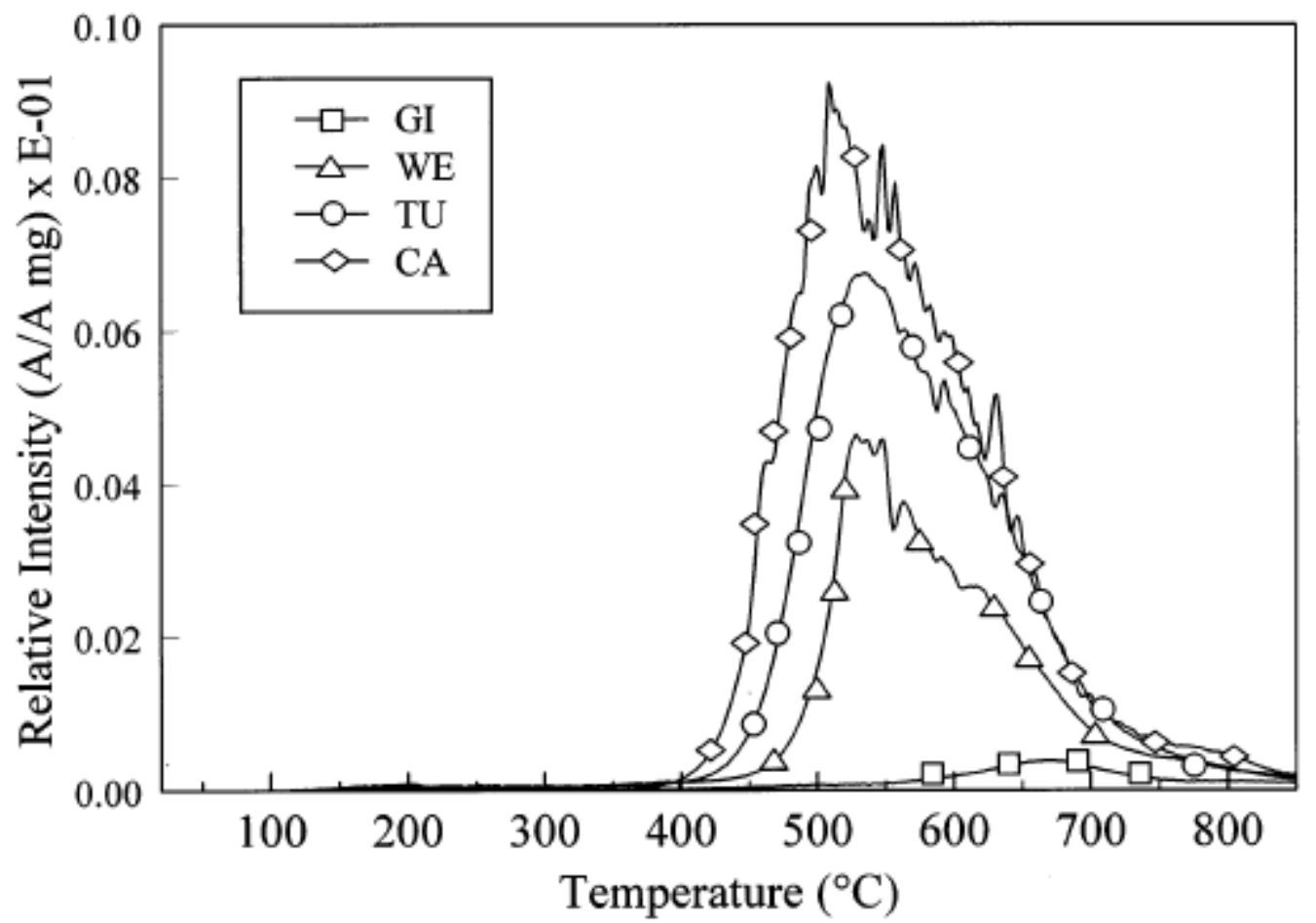

Figure 8. $\mathrm{CH}_{4}$ evolution curves followed by MS during pyrolysis of the four coals. 


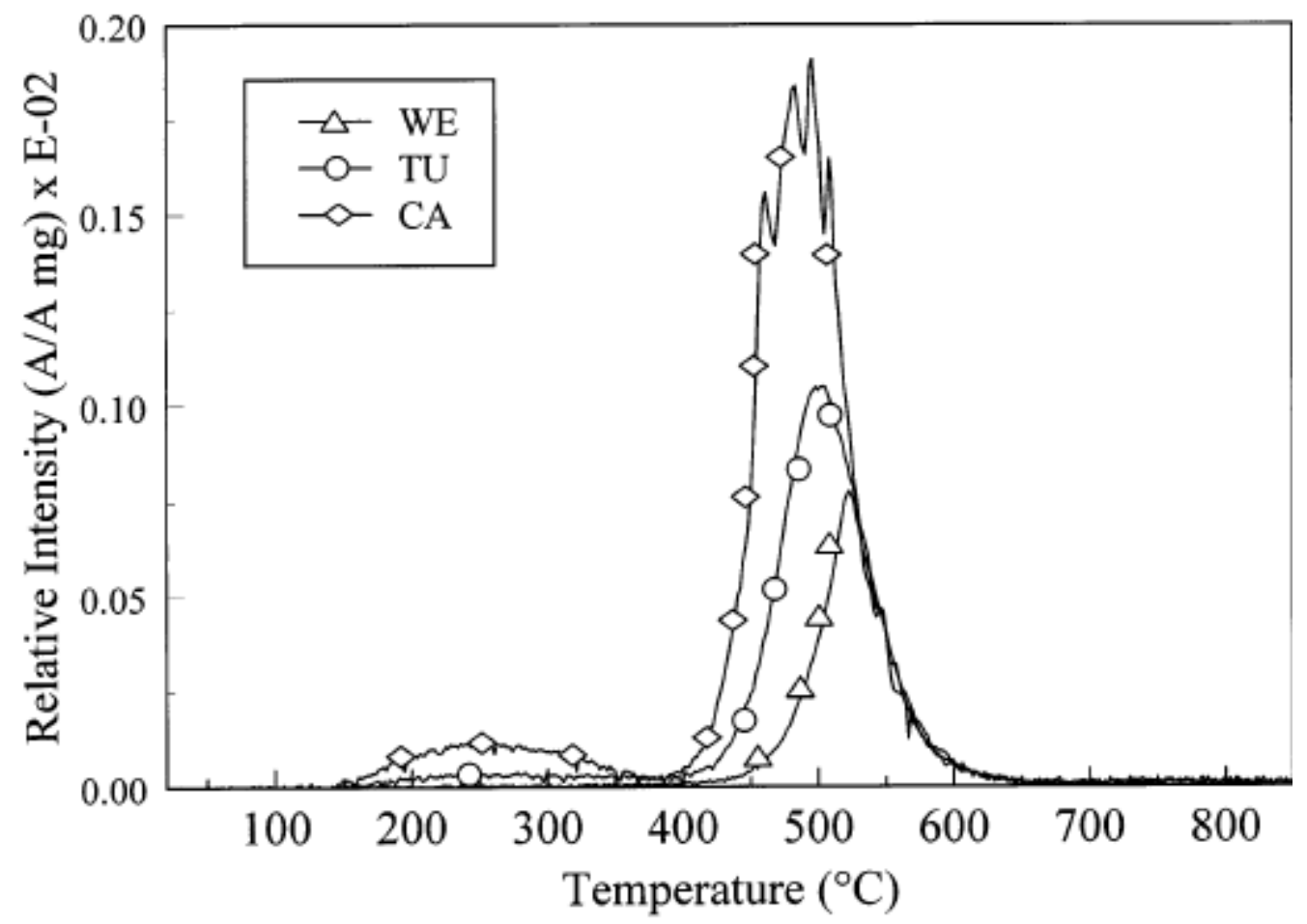

Figure 9. HCN evolution curves followed by MS during pyrolysis. 


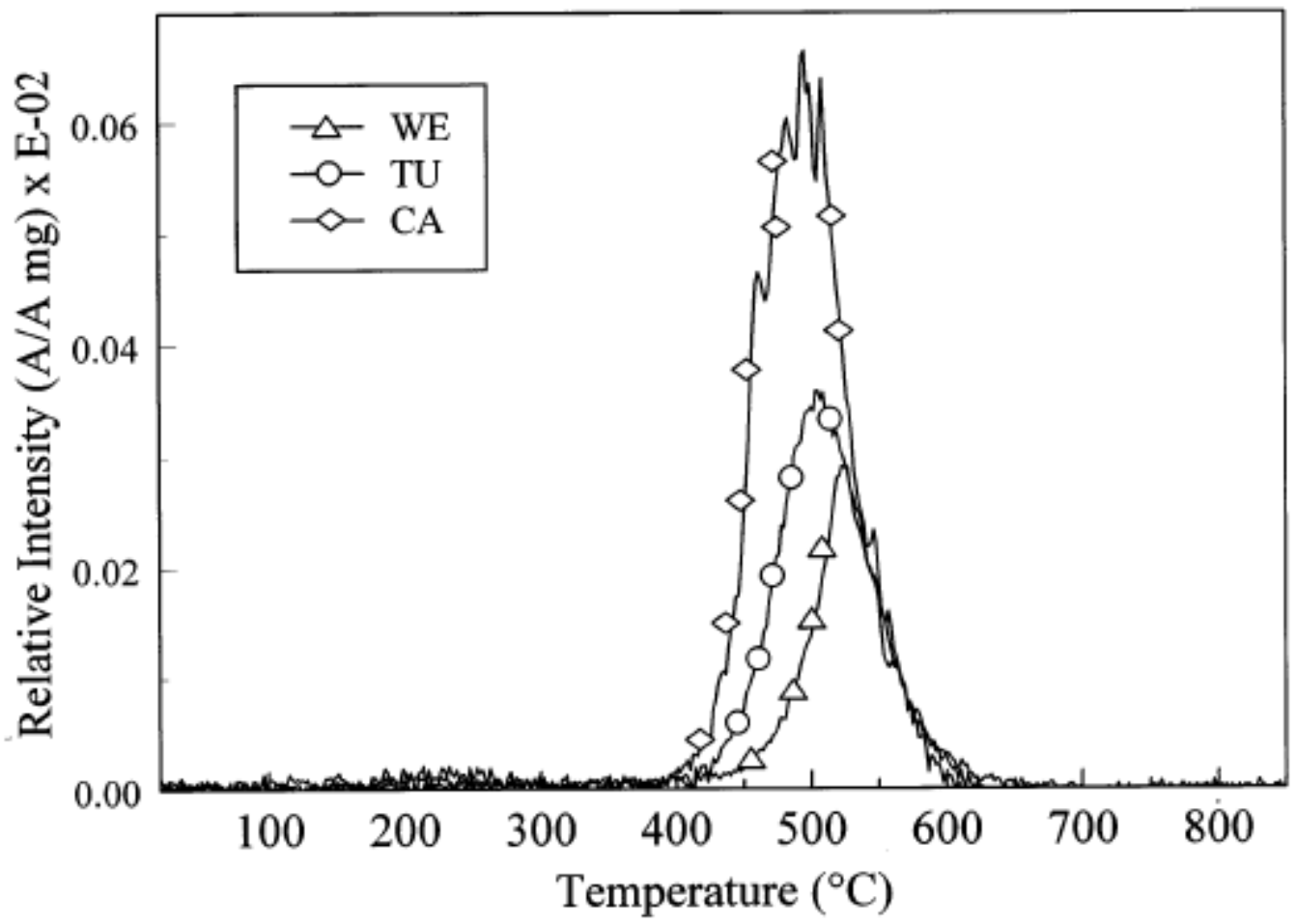

Figure 10. NO evolution curves followed by MS during pyrolysis. 


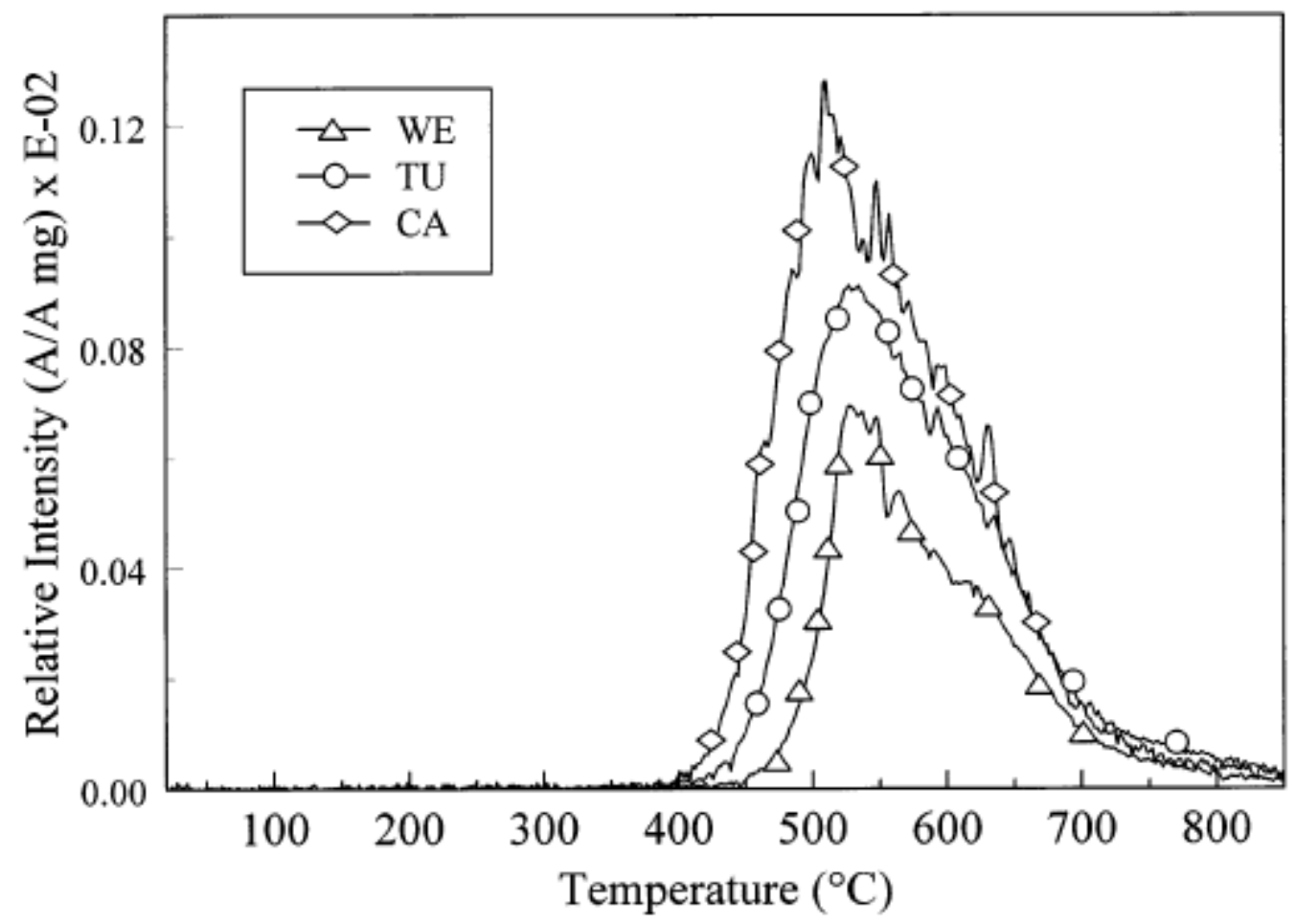

Figure 11. Evolution curves of the reduced species $\mathrm{N}_{2}{ }^{++}$followed by MS during pyrolysis. 